\title{
Profile of children with increased intracranial pressure on mannitol treatment
}

\author{
Sander D Teddy, MD; Abdul Latief, MD; Bambang Madiyono, MD
}

\begin{abstract}
Background Early recognition of increased intracranial pressure (IIP) and well-monitored management are determining indicators for treatment outcome. As far as we know, data of children with IIP on mannitol treatment has not been available.

Objective To elicit the profile of IIP patients who received mannitol at the Department of Child Health, Cipto Mangunkusumo Hospital, Jakarta.

Methods This was a cross-sectional study. Data were obtained from medical records of patients with increased intracranial pressure who received mannitol at the Department of Child Health, Cipto Mangunkusumo Hospital, Jakarta between July 2001 to October 2003

Results Fifty-four IIP patients with mannitol treatment were included. Forty-two (78\%) were under-five years old. Thirty-six subjects (67\%) were boys; 30 (56\%) were undernourished. Central nervous system infections (meningitis and encephalitis) were the most frequent causes of IIP. Most of the head CT scan revealed cerebral edema, hydrocephalus, and cerebral hemorrhage. Fifty subjects (93\%) had decline of consciousness; most of them were somnolent. Improvement in consciousness was identified in 31 subjects, in which 21 subjects reached full consciousness. Vomiting, which was found in 25 subjects (46\%), subsided after mannitol administration. Behavioral changes were found in 49 subjects (91\%); 32 subjects still had persistent behavioral changes after mannitol administration. Large and protruding fontanel was found in $7 / 22$ subjects, cerebral nerve paralysis in 23 subjects (43\%) and papillary edema in 6 of 34 subjects who underwent funduscopy. During the treatment with mannitol, fever was found in 5 subjects, vomiting in 2 subjects, skin edema and tachycardia each in 1 subject. Metabolic acidosis was found in 6/13 subjects, hyponatremia and hypokalemia in 16 and 13 out of 30 subjects respectively. Death occurred in 9 subjects (17\%).

Conclusion In IIP patients, the administration of mannitol has a tendency to improve consciousness, vomiting, and behavioral or personality changes. The high incidence rate of electrolyte imbalances and metabolic acidosis during the treatment indicated the need of periodic monitoring to detect early disorders. [Paediatr Indones 2004;44:148-152].
\end{abstract}

Keywords: increased intracranial pressure, mannitol, indicators
I ncreased intracranial pressure (IIP) is a neuropediatric emergency caused by multitude of events such as head trauma, encephalopathy, craniospinal infection, hydrocephalus, cerebral tumor, and intracranial hemorrhage. The etiology of IIP has to be identified, otherwise, the effects of IIP per se are more detrimental than the underlying process so that early recognition and well-monitored management are highly significant indicators for the treatment outcome. ${ }^{1-3}$

Management of IIP encompasses supportive measures, pharmacological therapy, surgery, and treatment of the causes. ${ }^{4,5}$ One of the pharmacological preparations frequently used is mannitol which has a diuretic effect, decreasing systemic blood volume and subsequently reducing cerebral blood volume with further outcome of decreasing intracranial pressure. 6,7 This study aimed to find out the profile of IIP patients who received mannitol at the Department of Child Health, Cipto Mangunkusumo Hospital, Jakarta.

\section{Methods}

This was a descriptive, retrospective study on the medical records of IIP patients who received mannitol and were hospitalized at the Department of Child

From the Department of Child Health, Medical School, University of Indonesia, Jakarta.

Request reprints to: Abdul Latief, MD, Department of Child Health, Medical School, University of Indonesia, Cipto Mangunkusumo Hospital, Jakarta, Indonesia. Tel.62-21-3907740, Fax.62-21-3907743. 
Health, Cipto Mangunkusumo Hospital, Jakarta, from July 2001 to October 2003. Nutritional status was assessed by weight for height $(\mathrm{W} / \mathrm{H})$ measurement. Well-nourished, undernourished, and malnourished, were defined if $\mathrm{W} / \mathrm{H}$ was $\geq 90 \%, 70-89 \%$, and $<69 \%$ of the Harvard $\mathrm{P}_{50}$ curve, respectively.

Encephalitis, meningitis, and encephalopathy were retrieved from the working diagnoses written in the medical records. Since we did not have an intracranial pressure measurement device, increased intracranial pressure was defined if the following clinical manifestations existed i.e., decline in consciousness, vomiting, headache, behavioral/personality changes, large and protruding fontanel, enlargement of the head circumference, paralysis of cranial nerves III, IV, VI, and papillary edema. This diagnosis was confirmed by the consultants of the Division of Pediatric Neurology, Department of Child Health, Cipto Mangunkusumo Hospital. Head circumference was measured in subjects less than 36 months of age, before the closure of sutures. Large fontanel was reported only in subjects less than 24 months of age. ${ }^{1,3}$

Metabolic acidosis, hyponatremia, hypokalemia, and clinical manifestations such as headache, chills, fever, tachycardia, urticaria, edema, and skin necrosis around the site where mannitol was administered, were regarded as the adverse effects of mannitol if the duration of those effects was along the administration time or at the longest, 4 hours following the administration of mannitol in subjects who previously had never complained of these effects. These adverse effects were limited to 4 hours based on the $\mathrm{T}^{1} 1 / 2$ of mannitol. Data collected from completely filled ques- tionnaires were processed using SPSS 11.0 computer program.

\section{Results}

Between July 2001 and October 2003 there were 64 IIP patients treated with mannitol, in which 54 of their medical records were collectible. The ratio of boys to girls was $2: 1$. Forty-two children (78\%) were under-five years of age. Thirty subjects (56\%) were diagnosed as having malnutrition. More details of the subjects' characteristics can be seen in Table 1 .

Table 1. Distribution of subjects' characteristics

\begin{tabular}{|c|c|c|}
\hline Characteristics & $\mathbf{N}$ & $\%$ \\
\hline \multicolumn{3}{|l|}{ Sex } \\
\hline Male & 36 & 67 \\
\hline Female & 18 & 33 \\
\hline \multicolumn{3}{|l|}{ Age group (year) } \\
\hline$<1$ year & 20 & 37 \\
\hline $1-<5$ years & 22 & 41 \\
\hline $5-<10$ years & 8 & 15 \\
\hline $\begin{array}{l}\geq 10 \text { years } \\
\text { (Median: } 1 \text { year } 7 \text { months) }\end{array}$ & 4 & 7 \\
\hline \multicolumn{3}{|l|}{ Nutritional status } \\
\hline Well-nourished & 23 & 43 \\
\hline Undernourished & 30 & 55 \\
\hline Malnourished & 1 & 2 \\
\hline \multicolumn{3}{|l|}{ Primary cause of IIP } \\
\hline Meningitis & 18 & 33 \\
\hline Encephalitis & 17 & 31 \\
\hline Cerebral hemorrhage & 10 & 18 \\
\hline Encephalopathy & 3 & 6 \\
\hline Cerebral tumor & 2 & 4 \\
\hline Leukemia cell infiltration & 2 & 4 \\
\hline Prolonged seizure & 2 & 4 \\
\hline
\end{tabular}

TABle 2. Distribution of Clinical MANifestations IN IIP SUBJECTS PRIOR to AND FOLLOWING MANNITOL ADMINISTRATION

\begin{tabular}{lcc}
\hline Clinical manifestation & Prior to mannitol & Following mannitol \\
\hline Declined consciousness $(n=54)$ & 50 & 33 \\
Vomiting $(n=54)$ & 25 & 2 \\
Headache $(n=6)$ & 4 & 2 \\
Behavioral change $(n=54)$ & 49 & 32 \\
Large and protruding fontanel $(n=22)$ & 7 & 3 \\
Enlargement of head circumference $(n=34)$ & 2 & 2 \\
Paralysis of cerebral nerves $(n=54)$ & 23 & 22 \\
Papillary edema $(n=34)$ & $66^{*}$ & 1 \\
Symptoms of cerebral herniation $(n=54)$ & 4 & 5 \\
\hline
\end{tabular}

* only 2 out of 6 were followed up after receiving mannitol treatment 
The underlying conditions of IIP in the study subjects are listed in Table 1. Head CT scan was performed on 30 subjects $(56 \%)$. The results revealed mostly cerebral hemorrhage, cerebral edema, and hydrocephalus. However, there were 3 IIP subjects who had normal CT scan results.

Table 2 reveals that 50 subjects $(93 \%)$ had declined consciousness; somnolent was the most frequent consciousness state found in 25 subjects. Four subjects had no declined consciousness; all had IIP due to head trauma. Improvement in consciousness degree was identified in 31 subjects, in which 21 subjects reached full consciousness. Vomiting, which was found in 25 subjects, subsided after mannitol administration. Two of 29 subjects who initially had no vomiting, vomited after the initiation of mannitol.

Headache was found in 6 subjects. Out of 4 subjects with headache, two subjects still complained of headache following mannitol administration. Forty-nine subjects experienced behavioral changes, but 32 still had persistent behavioral changes after mannitol administration. The number of subjects with large protruding fontanel was $7 / 22$; in 4 subjects, the protruding fontanel was resolved after mannitol administration. From 34 subjects aged less than 36 months, 2 subjects had enlargement of head circumference. Twentythree subjects had paralysis of cerebral nerves prior to mannitol administration. Improvement after treatment was observed in 2 subjects (9\%).

Funduscopy examination prior to mannitol administration was performed on 34 subjects. Out of them, six subjects had papillary edema. Repeated funduscopy examination following mannitol administration was performed on 2 subjects with papillary edema. Out of 28 subjects who previously had not had papillary edema, 17 subjects underwent repeated funduscopy examination and none had papillary edema.

The incidence of cerebral herniation prior to mannitol administration was found in 4 subjects. After mannitol treatment, three out of 4 subjects did not reveal symptoms of cerebral herniation anymore. Conversely, out of 50 subjects who previously had not showed any symptoms of cerebral herniation, after treatment with mannitol, 4 subjects showed symptoms of cerebral herniation.

Hyponatremia was the most frequent adverse effect found in this study, followed by metabolic acidosis and hypokalemia. Fever was found in 5 out of 54
Table 3. Distribution of adverse effects after MANNITOL ADMINISTRATION

\begin{tabular}{lll}
\hline Adverse effects & N & $\%$ \\
\hline Metabolic acidosis $(n=13)$ & 6 & 46 \\
Hyponatremia $(n=30)$ & 16 & 53 \\
Hypokalemia $(n=30)$ & 13 & 43 \\
Fever $(n=54)$ & 5 & 9 \\
Vomiting $(n=29)$ & 2 & 7 \\
Skin edema $(n=54)$ & 1 & 2 \\
Tachycardia $(n=54)$ & 1 & 2 \\
\hline
\end{tabular}

subjects (9\%) and vomiting was found in 2 out of 29 subjects who previously had not had these complaints.

\section{Discussion}

Increased intracranial pressure is frequently encountered in a variety of systemic as well as neurological diseases. ${ }^{2}$ In this study, central nervous system infections (meningitis and encephalitis) were the primary cause of IIP in 35 subjects (64\%). The high infection rate was probably attributed to young age and nutritional status that are often correlated with susceptibility to infection. Intracranial infection process leads to vasogenic and citotoxic edema so that IIP due to cerebral edema is diffuse. ${ }^{8-10}$

Osmotherapy $\left(\right.$ Mannitol $\left.^{\mathrm{R}}\right)$ is particularly indicated for cytotoxic edema. The principle is by administering a solution that will draw the extravascular fluid into the cerebral blood vessels. Mannitol can be maintained in the plasma and will create an osmotic gradient, which will draw fluid from the brain through the capillary walls into the lumen with the resultant of decreasing IIP. Decrease in the cerebral blood flow caused by mannitol, as well as other hyperosmolar properties, will also reduce the risk for formation of cerebrospinal fluid which later reduces intracranial pressure and improves clinical manifestations. $5,8,11,13$

One of the IIP symptoms is projectile vomiting without nausea. ${ }^{14,15}$ As there was no explanation about the nature of vomiting in this study, all vomiting events prior to the initiation of mannitol were regarded as vomiting due to IIP and all vomiting events during treatment with mannitol in subjects who previously had not had this complaint were dismissed as the adverse effects of mannitol administration. This study revealed that mannitol administration in IIP subjects tended to lower the incidence of vomiting. 
Sander D Teddy et al: Children with increased intracranial pressure on mannitol treatment

Headache in IIP was found in $99 \%$ of adult subjects or older children, whereas younger children probably manifested the headache as their behavior-irritability. ${ }^{14,15}$ In this study, headache was written in medical records as a complaint found in 4 out of 6 subjects. This might be higher if irritability in the subjects regarded as headache and older children were inquired about this complaint.

Paralysis of cerebral nerves because of IIP is usually reversible. ${ }^{3,15}$ Ophthalmological paralysis was found in $23(43 \%)$ subjects. After the administration of mannitol, only 2 (9\%) subjects showed improvement. The low improvement rate of the cerebral nerves paralysis was probably due to the shortness of follow up time after mannitol administration. One new subject with cerebral nerve paralysis was found during the administration of mannitol. It was probably due to the progressiveness of the primary disease or missed finding before.

Identification of papillary edema in IIP at the early stage is very essential. Despite the fact that papillary edema is typical in IIP, it is seldom found in acute IIP and in children whose large fontanel has not closed and the sutures have not fused. ${ }^{3}$ From 34 subjects who underwent funduscopy prior to the administration of mannitol, papillary edema was found in 6 subjects (18\%). Repeated funduscopic examination after mannitol administration was only done in 2 subjects with the results of disappearance of papillary edema in 1 subject. According to literature, papillary edema will reverse to normal if IIP can be corrected at the early stage. ${ }^{16}$ The low rate of papillary edema in this study was probably due to the small number of subjects.

The most frequent cause of death in IIP is cerebral herniation. ${ }^{2,3}$ After the administration of mannitol, symptoms of cerebral herniation disappeared in 3 out of 4 subjects. While another 4 subjects revealed symptoms of cerebral herniation after the administration of mannitol. The causes of IIP in these 4 subjects were cerebral hemorrhage in 2 subjects, cerebral tumor and encephalitis each in 1 subject, so the herniation was probably attributed to the process of the diseases themselves. In cerebral hemorrhage, mannitol is contraindicated. In our subjects, cerebral herniation probably developed after mannitol administration. All of the subjects with cerebral herniation after mannitol treatment (5 subjects) died.
The adverse effects of mannitol administration are dehydration, headaches, dizziness, chills, fever, tachycardia, chest pain and so on. Hypersensitivity effect appears as urticaria. Rapid intravenous administration can shrink erythrocytes, whereas extravasations can cause edema, inflammation, skin necrosis, or thrombophlebitis. The effects on the central nervous system are changes in mental status, lethargy, stupor, coma, even death..$^{711,17}$

The subjects of this study had been treated with combination of drugs. It is therefore difficult to identify the exact results as well as adverse reaction of mannitol. Exclusively, mannitol tended to improve consciousness, vomiting, and behavioral changes in IIP subjects. However, there were hyponatremia in 16/30 subjects, hypokalemia in 43\%, and metabolic acidosis in 6/13 subjects. The adverse effect such as fever was found in 5 subjects (9\%), vomiting in $2 / 29$ subjects, skin edema and tachycardia each in 1 subject (2\%).

As a conclusion, in IIP patients, the administration of mannitol tends to improve consciousness, vomiting, and behavioral or personality changes. Electrolyte and blood gas disorders were found in more than $50 \%$ of the subjects, requiring a standard protocol of mannitol administration that encompasses periodic monitoring for fluid, electrolyte, blood gas disorders, and other adverse effects imposed by mannitol.

\section{References}

1. Ismael S. Peninggian tekanan intrakranial. In: Soetomenggolo TS, Ismael S, editors. Buku Ajar Neurologi Anak. Jakarta: BP IDAI; 1999. p. 60-77.

2. Miller JD. Basic intracranial dynamics. In: Minns RA, editor. Problem of intracranial pressure in childhood. $1^{\text {st }}$ ed. London: Mac Keith Press; 1991. p. 1-12.

3. Larsen GY, Goldstein B. Increased intracranial pressure. Pediatr Rev 1999;20:234-9.

4. Miller RD. Anesthesia. $5^{\text {th }}$ edition. New York: Churchill Livingstone; 2000. p. 2467-72.

5. Allen $\mathrm{CH}$, Ward JD. An evidence-based approach to management of increased intracranial pressure. Crit Care Clin 1998;14:485-95.

6. Jackson EK. Diuretics. In: Wonsiewicz MJ, McCurdy P, editors. Goodman \& Gilman's, the pharmacological basis of therapeutics. $9^{\text {th }}$ ed. New York: McGraw-Hill; 1996. p. 685-714. 


\section{Paediatrica Indonesiana}

7. Cohen DS, Quest DO. Increased intracranial pressure, brain herniation, and their control. In: Wilkins RH, Rengachary SS, editors. Neurosurgery. $2^{\text {nd }}$ ed. New York: McGraw-Hill; 1996. p.345-56.

8. Morriss FC, Cook JD. Increased intracranial pressure. In: Levin DL, Morriss FC, Moore GC, editors. A practical guide to pediatric intensive care. $2^{\text {nd }} \mathrm{ed}$. St. Louis: Mosby Company; 1984. p. 47-53.

9. Kimelberg HK. Current concepts of brain edema. J Neurosurg 1995;83:1051-9.

10. Pollay M. Blood brain barrier; cerebral edema. In: Wilkins RH, Rengachary SS, editors. Neurosurgery. $2^{\text {nd }}$ ed. New York: McGraw-Hill; 1996. p. 335-44.

11. Dollery SR. Therapeutic drugs. Edinburg: Churchill Livingstone; 1991. p. M5-8.

12. Chasse R. Diuretic, erytropoietin, and other medications used in renal failure. In: Chernow B, editor. Es- sential of critical care pharmacology. $2^{\text {nd }}$ ed. Baltimore: William \& Wilkins; 1994. p. 432-9.

13. Cruz J, Miner ME, Allen SJ, Alves WM, Gennarelli TA. Continuous monitoring of cerebral oxygenation in acute brain injury: injection of mannitol during hyperventilation. J Neurosurg 1990;73:725-30.

14. Mardjono M, Sidharta P. Neurologi klinis dasar. $8^{\text {th }} \mathrm{ed}$. Jakarta: PT Dian Rakyat; 2000. p. 390-402.

15. Bruce DA. Neurosurgical emergencies. In: Fleisher GR, Ludwig S, Silverman BK, editors. Synopsis of pediatric emergency medicine. $1^{\text {st }}$ ed. Baltimore: Williams \& Wilkins; 1996. p. 764-8.

16. Friedman DI. Papilledema and pseudotumor cerebri. Ophthal Clin of North Am 2001;14:116-30.

17. Paczynski RP. Osmotherapy, basic concepts and controversies. Crit Care Clin 1997;13:105-29. 